\title{
Neuronal Pentraxin 1: A Novel Mediator of Hypoxic-Ischemic Injury in Neonatal Brain
}

\author{
Mir Ahamed Hossain, ${ }^{1,4}$ Juliet C. Russell, ${ }^{4}$ Richard 0’Brien, ${ }^{1,2}$ and John Laterra ${ }^{1,2,3,4}$ \\ Departments of ${ }^{1}$ Neurology, ${ }^{2}$ Neuroscience, and ${ }^{3}$ Oncology, The Johns Hopkins University School of Medicine, and ${ }^{4}$ The Kennedy Krieger Research \\ Institute, Baltimore, Maryland 21205
}

\begin{abstract}
Neonatal hypoxic-ischemic brain injury is a major cause of neurological disability and mortality. Its therapy will likely require a greater understanding of the discrete neurotoxic molecular mechanism(s) triggered by hypoxia-ischemia (HI). Here, we investigated the role of neuronal pentraxin 1 (NP1), a member of a newly recognized subfamily of "long pentraxins," in the HI injury cascade. Neonatal brains developed marked infarcts in the ipsilateral cerebral hemisphere at $24 \mathrm{hr}$ and showed significant loss of ipsilateral striatal, cortical, and hippocampal volumes at $7 \mathrm{~d}$ after $\mathrm{HI}$ compared with the contralateral hemisphere and sham controls. Immunofluorescence analyses revealed elevated neuronal expression of NP1 in the ipsilateral cerebral cortex from $6 \mathrm{hr}$ to $7 \mathrm{~d}$ and in the hippocampal CA1 and CA3 regions from $24 \mathrm{hr}$ to $7 \mathrm{~d}$ after HI. These same brain areas developed infarcts and terminal deoxynucleotidyl transferase-mediated biotinylated UTP nick end labeling-positive cells within $24-48 \mathrm{hr}$ of HI. In primary cortical neurons, NP1 protein was induced $>2.5$-fold $(p<0.001)$ after their exposure to hypoxia that caused $\sim 30-40 \%$ neuronal death. Transfecting cortical neurons with antisense oligodeoxyribonucleotides directed against NP1 mRNA (NP1AS) significantly inhibited $(p<0.01)$ hypoxia-induced NP1 protein induction and neuronal death $(p<0.001)$, demonstrating a specific requirement of NP1 in hypoxic neuronal injury. NP1 protein colocalized and coimmunoprecipitated with the fast excitatory AMPA glutamate receptor subunit (GluR1) in primary cortical neurons, and hypoxia induced a time-dependent increase in NP1-GluR1 interactions. NPIAS also protected against AMPA-induced neuronal death $(p<0.05)$, implicating a role for NP1 in the excitotoxic cascade. Our results show that NP1 induction mediates hypoxic-ischemic injury probably by interacting with and modulating GluR1 and potentially other excitatory glutamate receptors.
\end{abstract}

Key words: neuronal pentraxin 1; hypoxic-ischemic neuronal death; antisense oligonucleotides; AMPA; excitotoxicity; primary cortical neurons

\section{Introduction}

A major cause of neurodevelopmental handicaps in children is hypoxic-ischemic brain injury from perinatal anoxia and insufficient cerebral blood flow (Lorenz et al., 1998). Survivors of such injury can experience substantial and lifelong neurologic disabilities for which currently there is no promising therapy (Johnston, 1997). There is evidence that excitotoxicity caused by overstimulation of the AMPA and NMDA subtypes of excitatory glutamate receptors plays a crucial role in hypoxic-ischemic injury in brain (McDonald et al., 1988; Choi and Rothman, 1990; Barks and Silverstein, 1992; Portera-Cailliau et al., 1997b; Johnston, 2001; Johnston et al., 2001). Furthermore, the neonatal brain is far more prone to excitotoxicity than the adult (McDonald et al., 1988; Choi and Rothman, 1990; Barks and Silverstein, 1992; Johnston, 2001; Johnston et al., 2001). However, the molecular mechanism(s) by which glutamate receptors are modulated

Received Sept. 23, 2003; revised March 18, 2004; accepted March 22, 2004

This work was supported by Grant 0030004 N (M.A.H.) from the American Heart Association (National) and National Institutes of Health Grant R01-HL 64408 (J.L.).

Correspondence should be addressed to Dr. Mir Ahamed Hossain, Department of Neurology, The Kennedy Krieger Institute, 707 North Broadway, Room 400-N, Baltimore, MD 21205. E-mail: hossain@kennedykrieger.org. DOI:10.1523/JNEUROSCI.0347-04.2004

Copyright $\odot 2004$ Society for Neuroscience $\quad$ 0270-6474/04/244187-10\$15.00/0 in response to hypoxia-ischemia (HI) remains essentially unknown.

The targeting and clustering of AMPA and NMDA receptors to synapses in the CNS is essential for efficient excitatory synaptic transmission (O'Brien et al., 1998). One of the earliest events in excitatory synapse formation is the clustering of postsynaptic glutamate receptors, and nearly all excitatory synapses are associated with postsynaptic glutamate receptor clusters (Petralia and Wenthold, 1992; Craig et al., 1993; Aoki et al., 1994; Baude et al., 1995; Lau and Huganir, 1995; O'Brien et al., 1998, 1999). The "long pentraxins," a newly recognized subfamily of proteins, have several structural and functional characteristics that might play a role in promoting excitatory synapse formation and synaptic remodeling (Schlimgen et al., 1995; Kirkpatrick et al., 2000). Included among these are the ability to form side-to-side and head-to-head multimeric aggregates (Gewurz et al., 1995; Goodman et al., 1996; Bottazzi et al., 1997) and the ability to bind other proteins via a lectin-like domain. Members of this subfamily include neuronal pentraxin 1 (NP1), neuronal activity-regulated pentraxin (Narp; also called NP2), and neuronal pentraxin receptor (Schlimgen et al., 1995; Goodman et al., 1996; Dodds et al., 1997; Kirkpatrick et al., 2000). Narp encodes a unique $\mathrm{N}$-terminal coiled-coil domain that is likely to mediate self aggregation and a single $\mathrm{C}$-terminal pentraxin domain that may be 
required for axonal transport and secretion (Goodman et al., 1996; Tsui et al., 1996; Dodds et al., 1997; O’Brien et al., 2002). The pentraxin domain on neuronal pentraxins is similar to the mammalian C-reactive protein and serum amyloid protein (Tsui et al., 1996). Narp shares these structural features with NP1, and both Narp and NP1 are secreted glycoproteins expressed exclusively in the CNS (Schlimgen et al., 1995; Goodman et al., 1996; Omeis et al., 1996; Dodds et al., 1997).

The physiological functions of neuronal pentraxins remain elusive, and NP1 function is essentially unknown. Most recently, O'Brien et al. (1998, 1999, 2002) showed that Narp regulates AMPA receptor clustering at synaptic sites. In contrast to Narp, a function for NP1 in neurons has not yet been identified. Exclusive expression of NP1 in the CNS, its characteristic feature as a secretory protein, and its large molecular size relative to the classical pentraxins ( $>50$ vs $30 \mathrm{kDa}$ ) suggest that NP1 may have novel unknown functions. Recently, DeGregorio-Rocasolano et al. (2001) found overexpression of NP1 in cerebellar granule neurons undergoing apoptosis, but the significance of this observation has been unclear. In the present study, using complementary in vitro and in vivo models, we found that NP1 is induced in hypoxic-ischemic brain injury and that antisense oligonucleotides directed against NP1 mRNA prevent hypoxia- and AMPAinduced neuronal death. We also found that NP1 colocalizes with GluR1 clusters and that hypoxia induces a time-dependent increase in NP1-GluR1 interactions. Our findings suggest a novel mechanism by which NP1 induction during HI accentuates excitotoxicity through interactions with GluR1 and potentially other glutamate receptor subtypes, thereby contributing to neuronal injury and death.

\section{Materials and Methods}

\section{Primary cortical cultures}

Cortical neuronal cultures were prepared from embryonic day 17 F344 rats (National Cancer Institute, Frederick, MD) as described (Wang et al., 2001; Jin et al., 2002). Cerebral hemispheres were removed aseptically and freed of meninges, olfactory bulbs, ganglia, and hippocampus. Pooled cortical tissues were incubated in $\mathrm{Mg}^{2+}$ - and $\mathrm{Ca}^{2+}$-free HBSS containing $0.025 \%$ trypsin, $6 \mu \mathrm{g} / \mathrm{ml}$ DNase, $1 \mathrm{mg} / \mathrm{ml}$ bovine serum albu$\mathrm{min}$, and $10 \mathrm{gm} / \mathrm{l}$ glucose for $15 \mathrm{~min}$ at $37^{\circ} \mathrm{C}$. Trypsinization was stopped with the addition of $1 \mathrm{mg} / \mathrm{ml}$ soybean trypsin inhibitor, and digests were centrifuged for $5 \mathrm{~min}$ at $1500 \mathrm{rpm}$. Resulting pellets were triturated with $10 \% \mathrm{FBS}$ and $10 \%$ horse serum containing trypsin inhibitor and DNase. The cell suspension was passed through a $70 \mu \mathrm{m}$ cell strainer (Falcon) and centrifuged for $3 \mathrm{~min}$ at $1500 \mathrm{rpm}$. Cells were resuspended in culture medium consisting of neurobasal medium (Invitrogen, Gaithersburg, $\mathrm{MD}), 2 \%$ B27 supplement, 2 mm L-glutamine, and 1\% penicillin-streptomycin (50 U/ml penicillin and $50 \mathrm{mg} / \mathrm{l}$ streptomycin) (Invitrogen). Cells were plated at $2.5 \times 10^{5}$ cells $/ \mathrm{cm}^{2}$ on $100 \mathrm{ng} / \mathrm{ml}$ poly-L-lysinecoated plates. Cultures were maintained in a humidified atmosphere containing $5 \% \mathrm{CO}_{2} / 95 \%$ air at $37^{\circ} \mathrm{C}$. At $3 \mathrm{~d}$ in vitro (DIV), one-third of the media was replaced with fresh medium (without L-glutamine) containing cytosine arabinofuranoside ( $5 \mu \mathrm{M}$; Sigma, St. Louis, MO) to arrest the growth of non-neuronal cells. With this protocol, $>95 \%$ of the cultured cells were cortical neurons, as determined by immunoreactivity for the microtubule-associated protein (Chemicon, Temecula, CA). Cultures were used for experiments after $6-7 \mathrm{~d}$ in culture.

\section{Unilateral cerebral hypoxia-ischemia}

Common carotid artery (CCA) occlusion combined with controlled hypoxia in postnatal day $8-10$ rat pups was performed as described by Trescher et al. (1997) to produce hypoxic-ischemic brain injury. Pups were separated from their mothers and placed in a temperaturecontrolled incubator set to an ambient temperature at $35^{\circ} \mathrm{C}$. Under deep inhalant anesthesia (isofluorane in an oxygen-nitrous oxide mixture delivered via a Drager vaporizer), a 5-6 mm incision was made in the neck, and the right common carotid artery was isolated, double ligated, and cut between the ligatures. After the surgical procedure, the animals recovered for $2 \mathrm{hr}$ in a temperature-controlled incubator, and then animals were placed in an enclosed, vented $500 \mathrm{ml}$ Plexiglas chamber that was partially submerged in $36^{\circ} \mathrm{C}$ water. Hypoxia was induced by continuous flow of warm, humidified gas ( $8 \%$ oxygen, balanced nitrogen) for $2 \mathrm{hr}$. After hypoxic exposure, the animals were again placed in the temperaturecontrolled incubator for $2 \mathrm{hr}$ before return to their dams to eliminate post-insult temperature variability that can influence the extent of injury. A subset of control animals were mock-treated with a small incision in their neck without CCA occlusion and placed in the Plexiglas chamber at normal air temperature (sham control). All procedures involving animals were performed in accordance with the NIH guide for the Care and Use of Laboratory Animals and were approved by The Johns Hopkins University Animal Care and Use Committee.

\section{Histochemistry and quantification of hypoxic-ischemic \\ brain injury}

Rat pups were killed at 6, 12, 24, and $48 \mathrm{hr}$, and $7 \mathrm{~d}$ after CCA ligation and hypoxia by perfusion fixation with $4 \%$ paraformaldehyde in PBS and then cryoprotected in $30 \%$ sucrose for quantification of brain injury and for immunohistochemical determination of NP1 induction. The extent of hypoxic-ischemic brain injury in control and hypoxic-ischemic animals was assessed by quantitative morphometric analysis using the well established computer-assisted image analysis software package, Microcomputer Imaging Device (MCID) (Imaging Research, Brock University, St. Catherines, Ontario, Canada), as described previously (Hossain et al., 1998). Briefly, serial $20 \mu \mathrm{m}$ coronal sections were stained with $0.5 \%$ cresyl violet. Brain injury was assessed in three regions: the posterior cerebral cortex, the anterior striatum, and the dorsal hippocampus. Coronal sections were selected at $200 \mu \mathrm{m}$ intervals spanning the entire striatum rostral to the anterior commissure as internal landmark, rostral to the caudal edge of the corpus callosum for posterior cerebral cortex, and caudal to the rostral-most edge of the hippocampus for dorsal hippocampus and were analyzed as described previously (Trescher et al., 1997; Hossain et al., 1998). The volumes were determined by the formula $\Sigma_{\mathrm{s}}\left(\right.$ cross-sectional area $\left.{ }_{s} \times 200\right)$ with $s=$ each individual sections. The percentage of injury volumes ipsilateral $(I)$ and contralateral $(C)$ to the carotid artery ligation was calculated by the formula $I / C \times 100$. In addition, to absolute injury volumes, the percentage of hemisphere injured was calculated in each animal and compared in control and experimental animals.

\section{Triphenyltetrazolium chloride staining}

Animals were killed by decapitation at 24 and $48 \mathrm{hr}$ after HI. Brains were removed and sliced into 2.0-mm-thick sections. Brain slices were incubated in $20 \mathrm{gm} / \mathrm{l}$ triphenyltetrazolium (TTC) chloride in PBS for $15 \mathrm{~min}$ at $37^{\circ} \mathrm{C}$ and then transferred to a $3.7 \%$ paraformaldehyde solution for fixation (Wang et al., 2001). Images of the area of infarction were visualized with a digital scanner (ArtixScan, Microtek, Taiwan).

\section{Immunofluorescence}

Representative coronal brain sections $(20 \mu \mathrm{m})$ from control and hypoxicischemic animals were washed with warm $10 \mathrm{~mm}$ sodium citrate, $\mathrm{pH}$ 6.0, for $1 \mathrm{~min}$. Brain sections were treated with $0.25 \%$ pepsin in $0.01 \mathrm{~N} \mathrm{HCl}$ for $15 \mathrm{~min}$ at room temperature (RT), washed three times with PBS, and incubated in $0.5 \%$ Triton X-100 for an additional hour. After washing with PBS, sections were blocked with 5\% normal goat serum in PBS containing $0.5 \%$ Triton X-100 for $1 \mathrm{hr}$, and then incubated overnight with mouse anti-rat monoclonal NP1 primary antibody (Ab) (1:500) (Transduction Laboratories, Temecula, CA). Negative controls were performed under identical conditions by incubating with an equal amount of nonimmune IgG instead of primary Ab. Sections were washed three times with PBS and incubated with FITC-conjugated goat anti-mouse secondary Ab (1:500) (Jackson ImmunoResearch, West Grove, PA) and 4,6-diamino-2-phenylindole (DAPI) for $1 \mathrm{hr}$ at RT. DAPI stains all cell nuclei in perfusion-fixed sections with blue fluorescence regardless of viability. Sections were coverslipped with Prolong mounting medium (Molecular Probes, Eugene, OR).

Double, live immunostaining of primary cortical cultures (grown on 
coverslips) with NP1 and GluR1 Ab (O’Brien et al., 1997) was conducted to determine NP1-GluR1 colocalization. Cortical neurons at 6-8 DIV were incubated with NP1 (1:200) and GluR1 (1:150) antibodies for 45 min at $37^{\circ} \mathrm{C}$ according to our previously described method (O'Brien et al., 1999, 2002). For negative controls, appropriate nonimmune IgG was used instead of primary antibodies. Neurons were then fixed with $3.7 \%$ formaldehyde, and permeabilized cells were stained with multiple fluorochrome-conjugated secondary antibodies (FITC-conjugated goat anti-mouse for NP1 and Texas Red-conjugated goat anti-rabbit for GluR1) and DAPI for $1 \mathrm{hr}$ at RT. Slides were coverslipped with Prolong mounting medium (Molecular Probes). NP1- and GluR1-specific immunofluorescence were visualized using a fluorescence microscope (Carl Zeiss Axioplan 1 microscope fitted with AxioVision 3.0 software) at 5 and $40 \times$ magnifications and a confocal microscope (Carl Zeiss Axiovert 200 fitted with Ultraview software) at $100 \times$ magnification.

\section{In vitro hypoxia}

To induce hypoxia, primary cortical neurons cultured for 6-7 DIV were placed in neurobasal medium without B27 supplement for at least 2-4 hr before exposure to hypoxia. Hypoxia was induced by exposing cells to humidified $95 \% \mathrm{~N}_{2} / 5 \% \mathrm{CO}_{2}$ using modular incubator chambers (Billups-Rothenberg, Del Mar, CA) for $0-24 \mathrm{hr}$ at $37^{\circ} \mathrm{C}$. Control cultures were exposed to humidified $95 \%$ air $/ 5 \% \mathrm{CO}_{2}$ at $37^{\circ} \mathrm{C}$ in a similar incubator chamber for the same duration (Jin et al., 2002).

\section{Assessment of cell death}

Neuronal death and viability were determined by three independent complementary methods.

3-(4,5-Dimethylthiazol-2-yl)-2,5-diphenyl tetrazolium bromide assay. Cell viability was measured using the substrate 3-(4,5-dimethylthiazol2-yl)-2,5-diphenyl tetrazolium bromide (MTT; Sigma), which is reduced by cells with functional mitochondria and considered to be a biochemical index for cellular viability. The rate of MTT reduction to formazan indicates the cellular metabolic status and can be determined by a quantitative colorimetric assay as described previously (Hossain et al., 2002). Primary cortical neuronal cultures were incubated with MTT (125 $\mu \mathrm{g}$ / $\mathrm{ml}$ ) in growth medium for $1 \mathrm{hr}$ at $37^{\circ} \mathrm{C}$. The medium was then aspirated, and the formazan product was dissolved in $500 \mathrm{ml}$ dimethyl sulfoxide and quantified spectrophotometrically at $540 \mathrm{~nm}$ using a Spectra MAX 340 pc (Molecular Devices, Sunnyvale, CA) plate reader. The results are expressed as a percentage of absorbance measured in control normoxic cultures after subtracting the background absorbance from all values.

Lactate dehydrogenase assay. Lactate dehydrogenase (LDH) activity released in the media after hypoxic exposure was measured using the CytoTox96 nonradioactive cytotoxicity assay kit (Promega, Madison, WI) according to manufacturer's instructions. The amount of color formed by LDH reaction is proportional to the number of lysed cells and quantified by measuring wavelength absorbance at $490 \mathrm{~nm}$. Percentage of cell death was determined using the formula $\%$ cytotoxicity = hypoxic $\mathrm{LDH}$ release $\left(\mathrm{OD}_{490}\right) /$ maximum $\mathrm{LDH}$ release $\left(\mathrm{OD}_{490}\right)$ after correcting for baseline $\mathrm{LDH}$ release.

Terminal deoxynucleotidyl transferase-mediated biotinylated UTP nick end labeling staining. The DeadEnd fluorometric terminal deoxynucleotidyl transferase-mediated biotinylated UTP nick end labeling (TUNEL) system (Promega) was used to detect cell death in brain sections after HI and in cultured cortical neurons exposed to hypoxia. This method allows direct detection of nuclear DNA fragmentation, an important biochemical hallmark of cell death, by catalytically incorporating fluorescein12-dUTP at $3^{\prime}$-OH DNA ends. Brain sections and cortical cultures on coverslips were processed according to manufacturers' instructions. Negative controls were performed under identical conditions except for the omission of terminal deoxynucleotidyl transferase from the reaction buffer. Sections and cultured slides were counterstained with DAPI. Fluorescein fluorescence was visualized in a fluorescence microscope (Carl Zeiss Axioplan 1) with an excitation at $485 \mathrm{~nm}$ and an emission at 535 $\mathrm{nm}$. DAPI fluorescence (blue) was visualized with excitation and emission filters at 365 and $450 \mathrm{~nm}$, respectively.

\section{Coimmunoprecipitation of NP1 with GluR1}

Total cellular extracts from cortical cultures were prepared in immunoprecipitation buffer ( $10 \mathrm{~mm}$ sodium phosphate, $100 \mathrm{~mm} \mathrm{NaCl}, 1 \%$ Triton $\mathrm{X}-100$ ) containing phosphatase inhibitors ( $1 \mathrm{~mm}$ sodium vanadate, $2 \mathrm{~mm}$ sodium pyrophosphate, $1 \mathrm{~mm}$ sodium $\beta$-glycerophosphate) and $1 \times$ protease inhibitor mixture (Calbiochem, La Jolla, CA) according to the previously described method (O'Brien et al., 1999). One hundred micrograms of total proteins were subjected to immunoprecipitation followed by immunoblotting as described previously (Hossain et al., 2002; Walter et al., 2002). Briefly, the total volume of each sample was adjusted to $1 \mathrm{ml}$ with the respective buffer and incubated overnight with $1 \mu \mathrm{g}$ of GluR1 polyclonal antibody (pAb) (Chemicon) at $4^{\circ} \mathrm{C}$ with constant shaking. Negative controls were performed under identical conditions by incubating with equal amount of nonimmune IgG instead of primary Ab. Then $20 \mu \mathrm{l}$ of protein A/G-agarose conjugated beads was added to each sample and incubated for $2-4 \mathrm{hr}$ at $4^{\circ} \mathrm{C}$. The beads were collected by centrifugation $(1000 \times g$ for $5 \mathrm{~min}$ ), washed (three times) with ice-cold PBS, and boiled for $3 \mathrm{~min}$ in $50 \mu \mathrm{l}$ of $1 \times$ electrophoresis sample buffer ( $2 \times$ sample buffer consists of $1.0 \mathrm{ml}$ of glycerol, $0.5 \mathrm{ml}$ of $\beta$-mercaptoethanol (BME), $3.0 \mathrm{ml}$ of $10 \%$ SDS, $0.125 \mathrm{of} \mathrm{ml} 1.0 \mathrm{M}$ Tris$\mathrm{HCl}, \mathrm{pH}$ 6.7, and $1 \mathrm{mg}$ of bromophenol blue) (Santa Cruz Biotechnology, Santa Cruz, CA). Twenty microliters were subjected to Western blot analysis for NP1 protein using mouse anti-rat NP1 monoclonal antibody $(\mathrm{mAb})$ according to previously described methods (Hossain et al., 2002).

\section{SDS-PAGE and Western blot analyses}

SDS-PAGE and immunoblotting were performed according to the method of Laemmli (1970) with modifications as described previously (Hossain et al., 2002). Briefly, neuronal extracts were prepared using 100 $\mu \mathrm{l}$ of ice-cold lysis buffer RIPA (PBS 1×, 1\% IGEPAL CA-630, 0.5\% sodium deoxycholate, $0.1 \%$ SDS) containing $1 \times$ protease cocktail inhibitor set 1 (Calbiochem), sodium vanadate $(1 \mathrm{mM})$, sodium pyrophosphate $(2 \mathrm{~mm})$, and sodium $\beta$-glycerophosphate $(1 \mathrm{~mm})$ and stored at $-70^{\circ} \mathrm{C}$. Protein concentrations were determined using the Coomassie protein assay (Pierce, Rockford, IL) according to the manufacturer's instructions. Total proteins $(10 \mu \mathrm{g})$ were diluted in Laemmli buffer containing $\beta$-mercaptoethanol, heated at $100^{\circ} \mathrm{C}$ for $5 \mathrm{~min}$, electrophoretically resolved on a $4-20 \%$ gradient Tris-glycine precast gel (Invitrogen, Carlsbad, CA) at $140 \mathrm{~V}$ for $1 \mathrm{hr}$, and immunoblotted with specific $\mathrm{Ab}$ to NP1, GluR1, and actin. Horseradish peroxidase (HRP)-conjugated secondary antibodies (Jackson ImmunoResearch) were used at 1:1000 dilutions for $1 \mathrm{hr}$ at RT. HRP reaction product was visualized by enhanced chemiluminescence using an ECL Western blotting detection kit (Amersham Biosciences, Arlington Heights, IL). Digitized images were quantified by densitometry (Molecular Dynamics).

\section{Oligodeoxyribonucleotide synthesis}

A 21-base-long phosphorothioated antisense oligodeoxyribonucleotide (ODN) against the NP1 mRNA and its corresponding sense ODN were synthesized from Integrated DNA Technologies (Coralville, IA). The sequences were 5' -GCGTGCGGCGCGGCCGGCCAG-3' for the NP1 antisense ODN (NP1AS) and 5' -CTGGCCGGCCGCGCCGCACGC-3' for the corresponding sense ODN (NP1S). The phosphorothioated nucleotides are underlined. The NP1 ODN sequence corresponds to nucleotides 4-24, which immediately follow the first initiation codon of the coding sequence of the NP1 cDNA (DeGregorio-Rocasolano et al., 2001). The ODN sequences exhibited no similarity to any other known mammalian genes as determined by BLAST (basic local alignment search tool).

\section{Transient transfection}

The specific involvement of NP1 was examined by using phosphorothioated NP1 antisense and corresponding sense ODNs. Transient transfection of primary cortical neurons (DIV 6) with either antisense ODN or sense ODN was performed using LipofectAMINE 2000 reagents (Life Technologies) according to manufacturer's instructions. Briefly, cortical neurons were grown at a density of $2.5 \times 10^{5} \mathrm{cells} / \mathrm{cm}^{2}$ and placed in fresh neurobasal medium without antibiotic at 6 DIV. NP1AS or NP1S ODNs (0.5 $\mu$ g per well) LipofectaMINE complex (1:3 charge ratio) was prepared according to the manufacturer's instructions. The conditioned 
culture medium on the cells was removed and saved. The cultures were washed with BME, and then $0.5 \mathrm{ml}$ of transfection medium (BME without glutamine and antibiotics, at $37^{\circ} \mathrm{C}, \mathrm{pH} 7.4$ ) was added to the cultures. One hundred microliters of the DNA-LipofectAMINE complex mixture were added to each well, and cells were incubated at $37^{\circ} \mathrm{C}$ in a $5 \% \mathrm{CO}_{2}$ incubator for 3 hr. The transfection medium was then aspirated; cells were washed with fresh transfection medium and then replenished with previously saved conditioned medium (Li et al., 2000). Experimental treatments were initiated $\sim 30 \mathrm{hr}$ after transfection.

\section{Statistical analysis}

We used ANOVA StatView 5.0 software program for statistical comparisons involving multiple groups, followed by Bonferroni/Dunn post hoc test to determine significance.

\section{Results}

NP 1 is induced in hypoxic-ischemic brain injury in neonatal rats

Neonatal rats at postnatal day 8-10 were subjected to unilateral CCA ligation combined with $2 \mathrm{hr}$ of hypoxia as described in Materials and Methods. Control animals were mock-treated with a small incision in their neck (no CCA occlusion) and then placed in the Plexiglas chamber in normal air (sham controls). All animals survived these procedures with no delayed mortality and were killed at $6,12,24$, and $48 \mathrm{hr}$, and $7 \mathrm{~d}$ after HI. The hemisphere ipsilateral to the ligation appeared edematous at $12-24 \mathrm{hr}$ after $\mathrm{HI}$, and liquefaction was apparent by $48 \mathrm{hr}$ after HI. Although the severity of brain injury varied, TTCstained brain sections showed clear-cut infarction of the ipsilateral cerebral cortex and hippocampal areas (CA1 and CA3) compared with sham controls. MCID quantification revealed that 11 and $33 \%$ of the brain was infarcted at 24 and $48 \mathrm{hr}$, respectively, after HI (Fig. $1 A$ ). Computer-assisted quantitative morphometry of brain injury from Nissl-stained coronal sections resulted in a significant decrease in ipsilateral striatal volume $(20 \% ; p<0.05)$, cortical volume $(35 \% ; p<0.01)$ and hippocampal volume $(31 \%$; $p<0.05) 7 \mathrm{~d}$ after HI compared with the sham controls (Fig. $1 B$ ). No histological evidence of injury to the striatum, cortex, and hippocampus contralateral to the hemisphere of CCA ligation was observed. These results are consistent with that reported previously in the same animal model (Nakajima et al., 2000). We used this in vivo neonatal model of $\mathrm{HI}$ to determine whether $\mathrm{HI}$ alters neuronal NP1 expression.

We performed immunofluorescence analyses, using mouse anti-rat NP1 mAb, of brain sections obtained at 6, 12, 24, and 48 $\mathrm{hr}$, and $7 \mathrm{~d}$ after $\mathrm{HI}$ and from sham controls (as described above) to determine whether there is a temporal relationship between NP1 induction and cell injury. HI was found to induce NP1specific immunoreactivity (viewed with a $40 \times$ objective) in the ipsilateral frontal and parietal cortex from $6 \mathrm{hr}$ after HI onset (Fig. 2 A). Increased hippocampal NP1 immunofluorescence was localized in the pyramidal layer of CA 3 and CA1 regions, but not in the dentate gyrus (DG), from $24 \mathrm{hr}$ after HI onset (Fig. 2C). This result suggests that NP1 is induced in neurons before actual tissue loss. This elevated NP1-specific immunofluorescence in the cerebral cortex and hippocampus persisted for at least $7 \mathrm{~d}$ after HI (Fig. $3 A, B$ ). Further analysis of $7 \mathrm{~d}$ posthypoxic-isch-

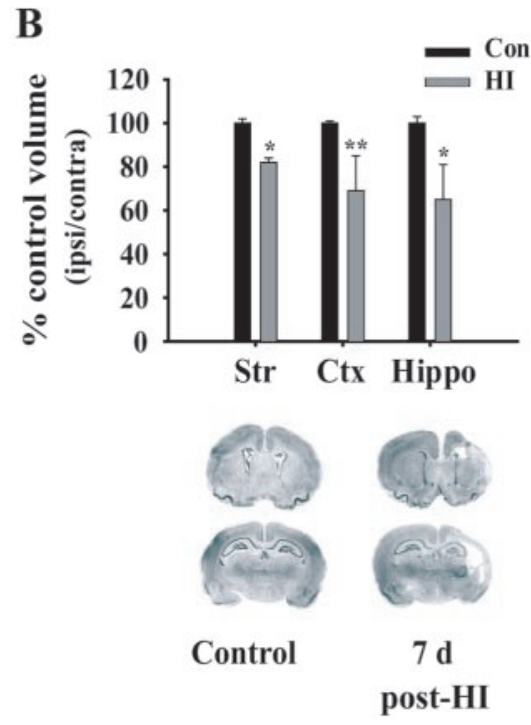

post-HI

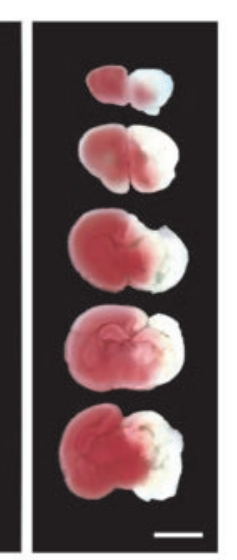

$48 \mathrm{~h}$ post-HI

Figure 1. Cerebral hypoxia-ischemia (HI)-induced injury in neonatal rat brain. The right CCA of neonatal rats was ligated. Rats Representative coronal brain sections are shown. Data represent mean $\pm \operatorname{SEM}\left(n=10 ;{ }^{*} p<0.05 ;{ }^{* *} p<0.01\right)$.

emic brain sections by confocal microscopy ( $100 \times$ objective) revealed intense NP1-specific fluorescence associated with individual neurons in the cortex and hippocampal CA1 and CA3 regions (Fig. $3 A$, right panels). No differences in NP1-specific immunofluorescence were detected in the hippocampus and cerebral cortex contralateral to CCA ligation and sham controls (Figs. 2, 3).

To assess the role of NP1 induction in hypoxic-ischemic cell death, we performed TUNEL histochemistry for degenerated neurons from brain sections adjacent to those used for NP1 immunofluorescence described above. TUNEL-positive cells were detected at $12 \mathrm{hr}$ in the hypoxic-ischemic cerebral cortex. More intensely stained TUNEL-positive cells were found in the ipsilateral frontal and parietal cortex and pyramidal layer of CA1 from 24 to $48 \mathrm{hr}$ of $\mathrm{HI}$ (Fig. $2 \mathrm{~B}, \mathrm{D}$ ). A similar temporal pattern of activation of caspase-3, an important neuronal death effector in HI models (Chen et al., 1998; Namura et al., 1998), was found in the same brain areas after HI (data not shown). Furthermore, these TUNEL-positive cells showed both apoptotic and necrotic morphologies, which are consistent with previous findings in a similar neonatal rat model (Nakajima et al., 2000). The round darkly stained chromatin of nuclei from apoptotic cells (yellow arrows) contrasted with the diffusely stained chromatin in necrotic cells (red arrows). Thus the induction of NP1 in the ipsilateral cortical and hippocampal CA1 and CA3 that occurred 6-18 hr before the appearance of TUNEL-positive cells was consistent with a role for NP1 in the injury cascade.

NP1 is induced in primary cortical neuronal cultures exposed to in vitro hypoxia

Primary neuronal cultures provide an excellent model for investigating the molecular and intracellular signaling events that regulate neuronal injury-death and survival because of their high degree of cellular homogeneity (D’Mello et al., 1993; Dudek et al., 1997), their predictable expression of a neuronal phenotype in 


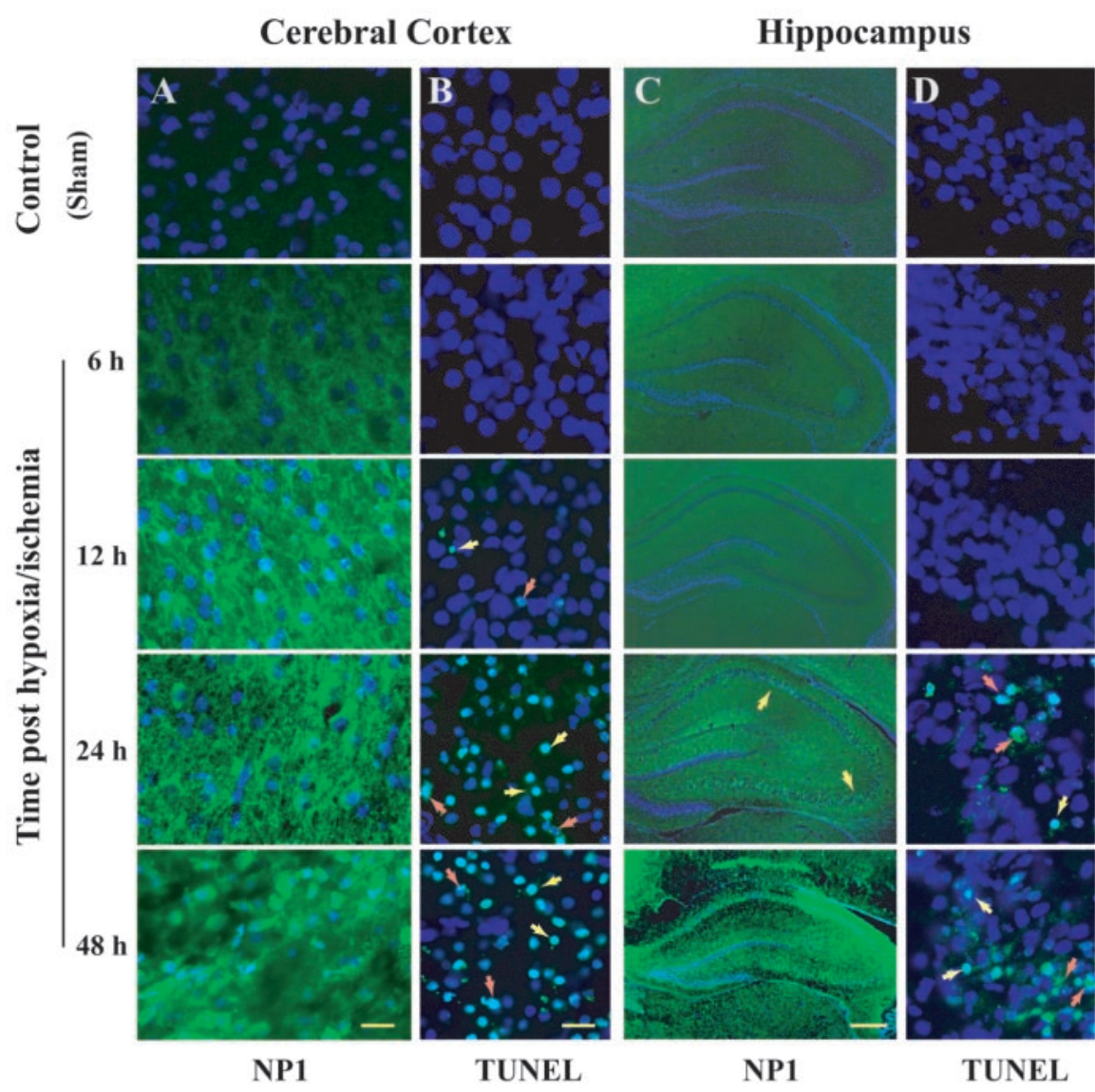

Figure 2. Temporal patterns of neuronal expression of NP1 after neonatal hypoxic-ischemic brain injury. Neonatal rats were killed at 6, 12, 24, and $48 \mathrm{hr}$ after HI. Representative coronal sections $(20 \mu \mathrm{m})$ from sham controls and $\mathrm{HI}$ rat brain were subjected to immunofluorescence using mouse anti-rat NP1 monoclonal primary and FITC-conjugated (green fluorescence) secondary antibodies. In A, NP1-specific immunoreactivity appeared at $6 \mathrm{hr}$ after $\mathrm{HI}$ in the ipsilateral cortex, and more intense NP1 immunofluorescence was detected from 12 to $48 \mathrm{hr}$ after $\mathrm{HI}$ compared with the contralateral hemisphere and sham controls (viewed at $40 \times$ magnification). In C, NP1-specific immunofluorescence was observed in the hippocampal pyramidal layer of CA1 and CA3 (shown by arrows) but not in the DG at 24 and $48 \mathrm{hr}$ after HI. Representative brain sections are shown at $5 \times$ magnification. In $B$ and $D$, Fluorometric TUNEL histochemistry of adjacent brain sections obtained from sham controls and at corresponding time periods after HI. Sections were counterstained with DAPI (dark blue) after TUNEL staining (green). Enhanced fluorescence of TUNEL-positive cells with darkly stained round chromatin (apoptotic cells; yellow arrows) and diffusely stained chromatin (necrotic cells; red arrows) was observed in the ipsilateral cerebral cortex at 12, 24 , and $48 \mathrm{hr}(B)$ and in the hippocampal CA1 (shown) (D) at 24 and $48 \mathrm{hr}$ after HI. No TUNEL-positive cells were found in the sham controls and in the contralateral hemisphere during the indicated time after $\mathrm{HI}$ (viewed at $40 \times$ ). Scale bars: $A, B, D, 20 \mu \mathrm{m} ; C, 200 \mu \mathrm{m}$.

vitro, including an extensive neuritic network, and their expression of multiple glutamate receptor subtypes (Cox et al., 1990). We extended our in vivo animal experiments to an in vitro model of hypoxia in primary cortical neuronal cultures to more directly examine the relationship between hypoxia and NP1 induction. Primary cortical neurons were cultured for $7 \mathrm{~d}$ in vitro, placed in neurobasal medium without B27 supplement for at least 2-4 hr, and then exposed to hypoxia for 12-14 hr. Control cultures were exposed to humidified 95\% air/5\% $\mathrm{CO}_{2}$ instead of hypoxia for the same duration of time (Jin et al., 2002). Light microscopic analysis of cortical neurons after exposure to hypoxia showed characteristic morphological changes of dying cells, which were round, smaller, and translucent, with disintegration of processes and cell bodies compared with control normoxic neurons (Fig. $4 A$ ). Control neurons were healthy and retained normal morphology, as indicated by larger size, phase brightness, and intact processes. Quantification of cell death by LDH release cytotoxicity assay, TUNEL staining, and MTT reduction revealed that hypoxia caused $\sim 30-40 \%$ neuronal death $(p<0.001)$ compared with the normoxic controls (Fig. $4 B-D$ ). This in vitro hypoxia model was used in subsequent experiments to determine the role of NP1 and its specific requirement for neuronal injury and death.

Next, we asked whether NP1 is induced in cultured primary cortical neurons in response to in vitro hypoxia. Western blot analysis of total cellular extracts revealed a specific band with apparent molecular mass of $\sim 47 \mathrm{kDa}$ consistent with the expected size of NP1 (Schlimgen et al., 1995; Kirkpatrick et al., 2000). Densitometric quantification and normalization to actin revealed $>2.5$-fold induction of NP1 protein at $3 \mathrm{hr}(273 \pm 23 \% ; p<0.001)$ and 6 hr $(255 \pm 24 \% ; p<0.001)$ of hypoxia compared with the normoxic controls set at $100 \%$ (Fig. $4 \mathrm{E}$ ). We found no difference in NP1 protein levels under normoxic conditions and at $0 \mathrm{hr}$ hypoxia time. The NP1 protein levels in normoxic controls were in a low but detectable range, consistent with that reported for cerebellar granule neurons under serum-free condition (DeGregorio-Rocasolano et al., 2001). These results confirm our detection of increased cortical and hippocampal neuronal NP1 immunoreactivity in vivo after HI.

\section{Antisense ODNs against NP1 inhibit in vitro hypoxia-induced NP1 protein expression}

To examine the mechanistic role of NP1 induction in hypoxic neuronal injury, we used an antisense knockdown strategy. First, we determined NP1 protein levels in cortical neurons transfected with an NP1 antisense ODN (NP1AS) for $\sim 30 \mathrm{hr}$ before exposure to hypoxia. We found that transfection of cortical neurons with NP1AS ODN completely inhibited ( $p<$ 0.01 ) induction of NP1 protein in response to hypoxia $(>2.0$-fold; $p<0.05$ ) (Fig. 5A). In contrast, NP1 sense ODN (NP1S) had no effect on NP1 induction by hypoxia. This result demonstrates that NP1 antisense ODN effectively inhibits the induction of NP1 protein expression in response to hypoxia. Furthermore, light microscopic analysis revealed that cortical neurons transfected with NP1AS maintained normal cellular morphology with intact processes after hypoxic exposure relative to normoxic control cultures. NPIS failed to preserve characteristics of normal cellular morphology after hypoxia (Fig. 5B).

\section{Antisense NP1 protects cortical neurons against hypoxia-induced neuronal death}

Next, we asked whether NP1 induction by hypoxia is directly involved in the neuronal death induced by hypoxia. Cortical neurons were transfected with either NP1AS or NP1S ODNs and then exposed to hypoxia. Neuronal death in response to hypoxia was assessed independently by complementary LDH release, TUNEL staining, and MTT cytotoxicity assays. Exposure of cortical neurons to hypoxia caused significant cell death $(\sim 30 \%$; $p<$ 
0.001 vs normoxia controls), as determined by LDH release in culture medium. Transfection of cortical neurons with NP1AS ODNs under conditions that inhibited NP1 protein induction (Fig. 5A) resulted in significant protection $(44 \%)$ against hypoxia-induced neuronal death compared with that in nontransfected neurons ( 21 vs $30 \%$ cell death; $p<0.001$ ) (Fig. 6A). Under similar conditions, quantification of TUNEL-positive cells showed $33 \%$ protection by NP1AS ( 21 vs $32 \%$ cell death; $p<0.001)$ compared with nontransfected cultures (Fig. 6B). Mitochondrial MTT reduction also revealed that NP1AS substantially increased neuronal viability after hypoxia when compared with nontransfected neurons (92 vs 59\%; $p<0.001$ ) (Fig. 6C). In contrast, NP1 sense oligonucleotides (NP1S) did not affect hypoxia-induced cell death in all three independent assays (Fig. 6A-C). Collectively these results demonstrate that NP1 gene silencing rescues primary cortical neurons from hypoxia-induced death. Our results provide the first evidence for NP1 function in central neurons and show that NP1 is part of the cell death program induced by hypoxia.

\section{NP1 interacts with the fast excitatory AMPA receptors}

We asked how NP1 induction contributes to neuronal injury triggered by hypoxia. Neuronal injury from cerebral hypoxiaischemia has been attributed to overstimulation of NMDA and AMPA subtypes of excitatory glutamate receptors (Choi and Rothman, 1990; Barks and Silverstein, 1992; Portera-Cailliau et al., 1997b). O'Brien et al. $(1998,1999)$ showed previously that the related pentraxin Narp plays a role in the clustering of excitatory AMPA receptors. We examined the relationship between NP1 and glutamate receptor clusters in primary neuronal cultures. Primary cortical neurons were established at low density (30$40 \times 10^{3}$ cells $/ \mathrm{cm}^{2}$ ). We performed live immunostaining of cortical neurons (DIV 7) with NP1 and GluR1 antibodies followed by staining with fluorochrome-conjugated secondary antibodies. Because NP1 is a secretory protein and undergoes axonal transport (Schlimgen et al., 1995), live staining of nonpermeable cells was performed to specifically examine cell-surface clustering and its colocalization with AMPA receptor GluR1 subunits. Microscopic analyses revealed immunofluorescence specific for NP1 (FITC-conjugated green fluorescence) and GluR1 (Texas Red fluorescence). Overlapping of digitized images revealed colocalization of NP1 with clusters of GluR1 subunits (Fig. 7A). No NP1- and GluR1-specific immunofluorescence was observed in cultures incubated with nonimmune IgG (negative controls). The specificity of this NP1 staining pattern was further demonstrated by examining neurons transfected with either NP1 antisense (NP1AS) or control NP1 sense (NP1S) ODNs. NP1-specific immunofluorescence disappeared in NP1AS-treated neurons but not in NP1S-treated neurons (Fig. 7A). We found no difference in NP1 and GluR1 immunofluorescence between NP1S-treated neurons and controls (data not shown). This result further confirms that NP1AS effectively inhibits NP1 expression in primary neuronal cultures. Our results show that NP1 colocalizes with GluR1 clusters and NP1 antisense oligonucleotides inhibit this
Hippocampus

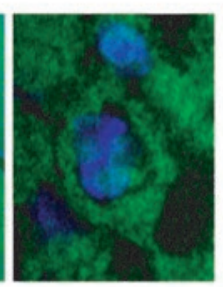

B Cerebral Cortex
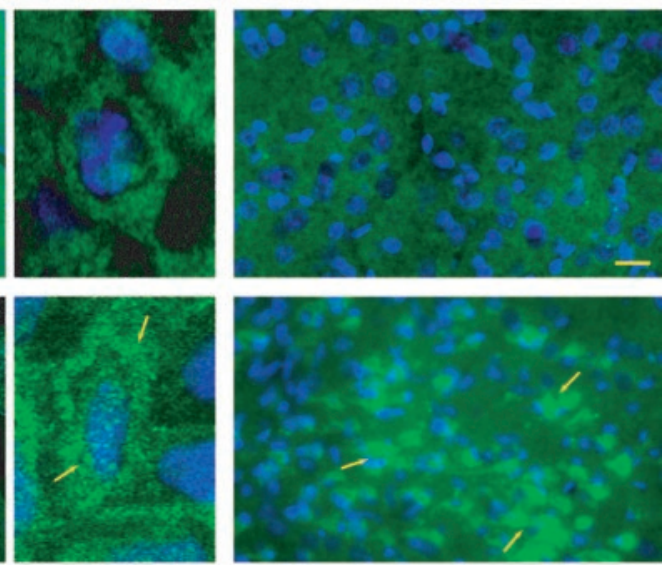
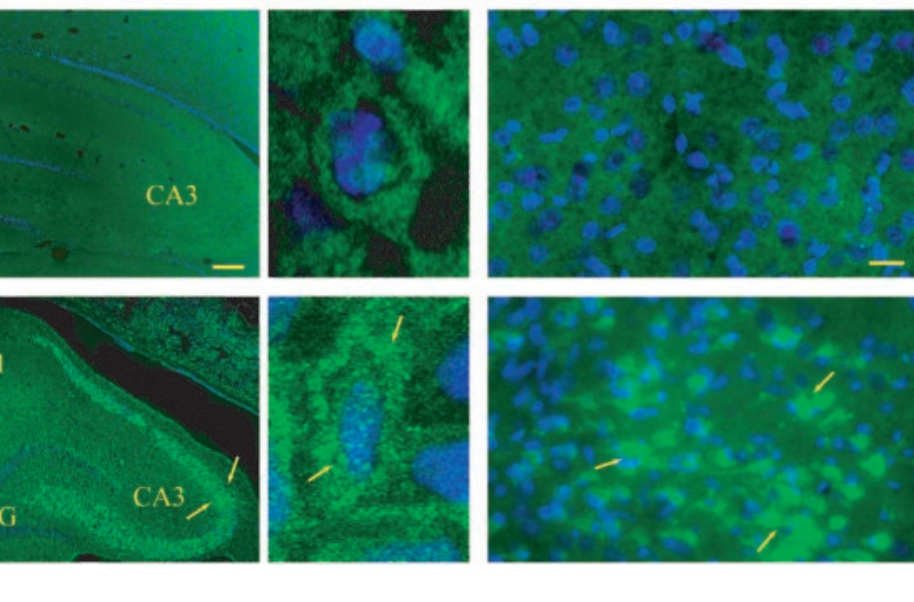

persists for a longer time period after neonatal $\mathrm{HI}$. Figure 3. NP1 induction in the ipsilateral cerebral cortex and hippocampus persists for a longer time period after neonatal HI.
Representative coronal brain sections $(20 \mu \mathrm{m})$ from sham controls and $7 \mathrm{~d}$ post-HI rats were analyzed for NP1-specific immunofluorescence as described in Materials and Methods. $A$, A high level of NPI immunoreactivity was observed in the ipsilateral cations. $B, A$ similar increase in NP1 immunoreactivity was observed in the frontal and parietal cortex of brain sections from

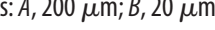

colocalization. We further examined this colocalization of NP1 with GluR1 in rat brain sections double immunostained with NP1 and GluR1 antibodies. Confocal microscopic analysis ( $100 \times$ objective) of cortical regions and merged digitized images showed neuronal colocalization of NP1 and GluR1 subunits (Fig. 7B).

The specific interaction of NP1 with GluR1 subunits was further demonstrated by complementary coimmunoprecipitation followed by Western immunoblotting analyses. Total cellular extracts of primary cortical cultures exposed to either hypoxia or normoxia were immunoprecipitated with GluR1 Ab and analyzed by Western immunoblotting. NP1 co-precipitated with GluR1 subunits and densitometric quantification showed a timedependent increase (approximately threefold; $p<0.001$ ) in NP1/ GluR1 ratio in response to hypoxia (Fig. $7 C$ ). To demonstrate the specificity of coimmunoprecipitation, we used nonimmune IgG instead of GluR1 Ab in a subset of samples. Western analysis of IgG immunoprecipitates showed no evidence of NP1- and GluR1-specific protein bands, thus excluding the possibility of nonspecific precipitation. This result shows a physical association between NP1 and GluR1 and that hypoxia induces NP1-GluR1 interactions and the recruitment of NP1 to GluR1 receptor subunits.

Antisense NP1 protects against AMPA-induced excitotoxicity The above results suggest a mechanism in which NP1 modulates hypoxic injury by altering excitatory glutamate receptor function through direct interactions with AMPA and potentially other glutamate receptor subtypes. We asked directly whether NP1 modulates AMPA-mediated neuronal death. Primary cortical neuronal cultures at 6-8 DIV were exposed to various concentrations of AMPA (10-300 $\mu \mathrm{M})$ as described previously for primary cerebellar granule neurons (Hossain et al., 2002). Exposing cortical cultures to $100 \mu \mathrm{M}$ AMPA for $24 \mathrm{hr}$ caused $\sim 40-50 \%$ cell death $(p<0.001)$ compared with controls (Fig. $8 A)$. This is comparable with the extent of cell death observed in our in vitro hypoxia experimental model (Fig. 4). We found that the AMPA receptor-specific inhibitor CNQX $(10 \mu \mathrm{M})$ significantly protected neurons from AMPA-mediated death (86 vs $46 \%$ cell 
A

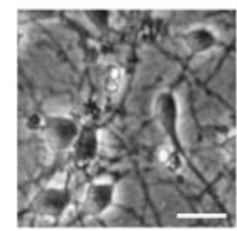

Normoxia

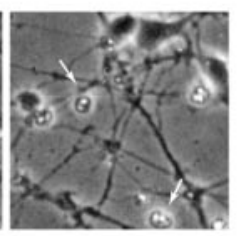

Hypoxia
B

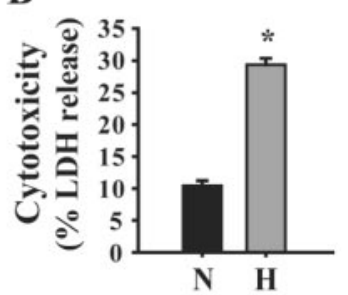

C

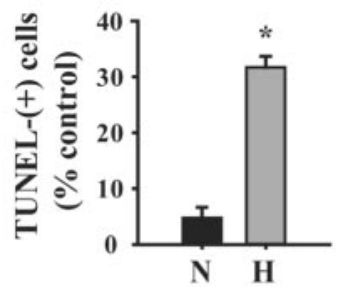

D

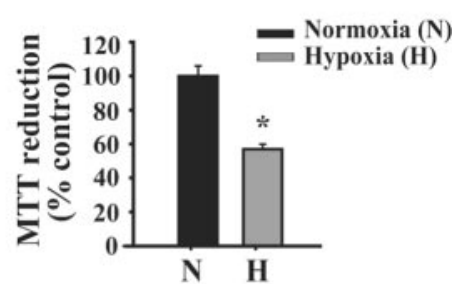

$\mathbf{E}$

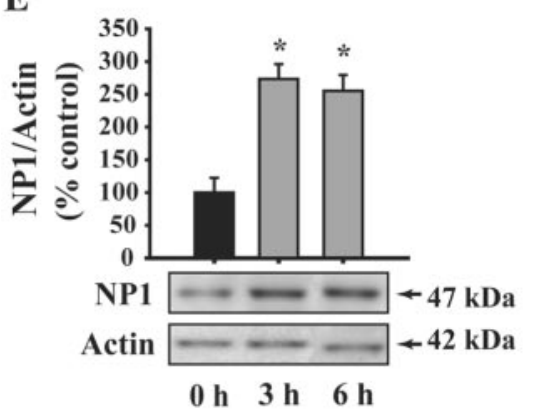

Figure 4. In vitro hypoxia causes substantial neuronal death and induces NP1 protein expression in primary cortical cultures. Primary cortical neurons cultured for $6-8 \mathrm{~d}$ in vitro were placed in neurobasal medium without B27 supplement for $2 \mathrm{hr}$ before exposure to hypoxia. $A$, Morphological evidence of injury and death in cortical neurons exposed to hypoxia for 12-14 hr. Scale bar, $20 \mu \mathrm{m}$. Quantification of cell death by LDH release (B), by TUNEL-positive staining $(C)$, and by MTT reduction $(D)$ revealed $\sim 30-40 \%$ cell death in response to hypoxia. Data are expressed as percentage of control normoxic cells (mean $\pm \mathrm{SEM} ; n=8$; ${ }^{*} p<0.001$ ). E, Total cellular proteins (20 $\mu \mathrm{g}$ per lane) were analyzed by SDS-PAGE and immunoblotted for NP1 expression in cortical cultures exposed to 0,3 , and $6 \mathrm{hr}$ of hypoxia and normoxia controls. Chemiluminescent detection shows an intense NP1-immunoreactive protein band at $\sim 47 \mathrm{kDa}$. Digitized images of NP1 band were quantified by densitometry and normalized to actin. Data represents percentage of normoxic controls (mean $\pm \mathrm{SEM} ; n=5-6 ;{ }^{*} p<0.001$ ). Blots shown are from representative experiments. $\mathrm{N}$, Normoxia; $\mathrm{H}$, hypoxia.

viability; $p<0.001$ ) (Fig. $8 B$ ). To determine whether there is a role for NP1 in AMPA receptor-specific excitotoxicity, we transfected cortical neurons with either NP1AS or NP1S ODNs. Approximately $30 \mathrm{hr}$ after transfection, cultures were exposed to 100 $\mu \mathrm{M}$ AMPA for $24 \mathrm{hr}$. MTT colorimetric assay revealed that NPIAS also protected $(p<0.05)$ against AMPA-induced neuronal death, although not as potently as CNQX (Fig. $8 B$ ). In contrast, NP1S ODN did not affect AMPA-induced cell death. Our results indicate that NP1 directly modulates AMPA receptor-mediated neuronal death.

\section{Discussion}

This study identifies NP1 as a novel molecular mediator of hypoxic-ischemic injury in brain. In demonstrating this we also show that inhibiting NP1 induction significantly prevented hypoxia-induced neuronal death. This is the first evidence for a pathophysiologic function of NP1 in central neurons and shows that NP1 is part of the death program induced by hypoxia-
$\mathbf{A}$

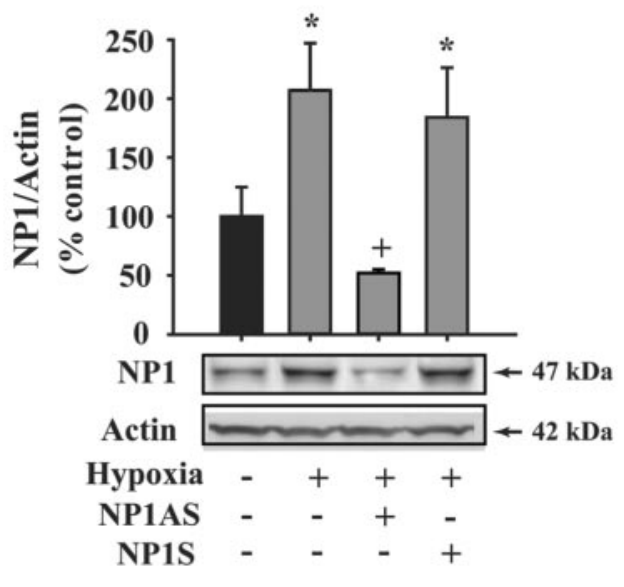

B

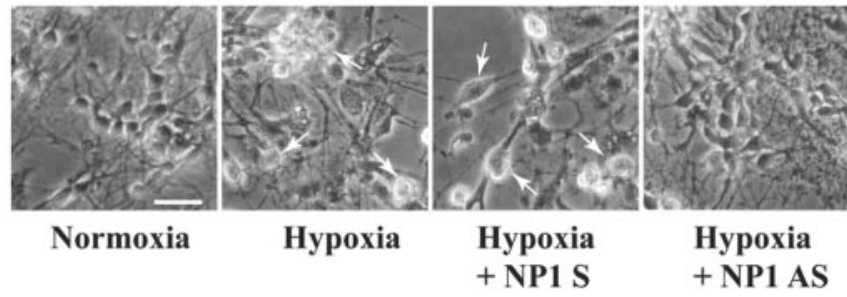

Figure 5. Inhibition of hypoxia-induced NP1 protein expression by NP1 antisense (NP1AS) ODNs. Cortical neuronal cultures at 6 DIV were transfected with phosphorothioated antisense (NP1AS) or sense (NP1S) ODNs (0.5 $\mu \mathrm{g})$, respectively, as described in Materials and Methods. Approximately $30 \mathrm{hr}$ later cells were exposed to hypoxia. Control transfected cells were incubated under normoxic condition. $A$, Immunoblotting for NP1 expression in cortical neurons transfected with either NP1 antisense or sense ODNs. NP1AS completely inhibited hypoxiainduced NP1 protein expression. The graph summarizes densitometric quantification of NP1 protein, normalized to actin, and is expressed as percentage of control normoxic cells (mean \pm SEM; $n=4 ;{ }^{*} p<0.05$ vs normoxia; ${ }^{+} p<0.01$ vs hypoxia). Representative immunoblots for NP1 and actin are displayed. B, Phase-contrast photomicrographs of primary cortical neurons exposed to hypoxia. Cortical neurons transfected with NP1AS maintained normal morphology with intact processes after hypoxia relative to normoxic cells. NPIS failed to preserve characteristics of normal cellular morphology after hypoxia. Scale bar, $20 \mu \mathrm{m}$.

ischemia. Particularly interesting and important findings in this report are the association of NP1 with the fast excitatory glutamate receptor AMPA, the hypoxia-induced time-dependent increase in NP1-GluR1 interactions, and the modulation of AMPA receptor-mediated neuronal injury and death by NP1. These results suggest a novel mechanism by which NP1 might accentuate excitotoxicity through interactions with GluR1 and potentially other glutamate receptor subtypes.

Hypoxia-ischemia in developing brain rapidly disrupts many excitatory circuits that promote activity-dependent neuronal plasticity (McDonald et al., 1988; Choi and Rothman, 1990; Barks and Silverstein, 1992; Johnston, 2001; Johnston et al., 2001) by causing a buildup of an extracellular glutamate pool, excessive activation of glutamate receptors, and activation of several downstream cytotoxic pathways (Choi and Rothman, 1990; McDonald and Johnston, 1990; Johnston et al., 2001). Early HI-induced neuronal death occurs through necrosis (primary damage) (Northington et al., 2001b). The delayed neuronal death (secondary damage) that occurs hours or days later is believed to be primarily apoptotic (Puka-Sundvall et al., 1997; Northington et al., 2001a). This apoptosis-necrosis morphological continuum of neuronal death after HI (Nakajima et al., 2000; Johnston et al., 2001) is similar to that observed in neonatal rats after excitotoxic activation of NMDA and non-NMDA glutamate receptors, sug- 
gesting that hypoxic-ischemic neuronal injury is triggered by the excitotoxic cascade (Portera-Cailliau et al., 1997a; Martin et al., 1998; Bittigau et al., 1999). We found that $\mathrm{HI}$ in neonatal brain induced NP1 immunoreactivity within 6-24 hr of hypoxic-ischemic insult, specifically in the ipsilateral-cortical (frontal and parietal cortex) and -hippocampal (pyramidal layers CA3 and CA1) regions that ultimately developed infarction at $24-48 \mathrm{hr}$ after HI. The increased NP1 immunoreactivity persisted for a longer time period ( $7 \mathrm{~d}$ examined) after HI. The ipsilateral forebrain that includes frontal and parietal cortex is the most vulnerable ischemic core region in the HI model used in this study (Rice et al., 1981). In fact, we found evidence of apoptotic and necrotic cell death in the ipsilateral cortex and hippocampal infarct areas by the presence of TUNEL-positive cells at $24 \mathrm{hr}$ after HI. This temporal and regional pattern of cell death is also supported by our findings of caspase- 3 activation in the same brain areas within 12-48 hr of HI (data not shown). This is consistent with previously reported increase in caspase-3 expression in the injured hemisphere at $24 \mathrm{hr}$ to $7 \mathrm{~d}$ after $\mathrm{HI}$ in a similar neonatal rat model (Nakajima et al., 2000). Thus, the observed induction of NP1 in response to $\mathrm{HI}$ with subsequent cell death within the ischemic core and the adjacent brain regions (i.e., hippocampus) suggests a plausible role of NP1 in the apoptotic and necrotic cell death initiated by HI. Our finding that NP1 expression is induced in primary cortical neurons under hypoxic conditions that induce significant neuronal death further validated these in vivo findings. Interestingly, the time course of NP1 induction by hypoxia revealed that NP1 protein expression precedes neuronal death. Thus it appears that NP1 induction contributes to an upstream component of the death cascade possibly before neurons commit to die.

NP1 is closely related to Narp (NP2) and shares similar structural features, sequence homology, and functional domains (Schlimgen et al., 1995; Goodman et al., 1996; Tsui et al., 1996; O’Brien et al., 2002). We found that NP1 is induced in response to $\mathrm{HI}$ primarily in the hippocampal pyramidal layers of CA3 and CA1, in contrast to that reported for Narp, which is expressed primarily in the hippocampal dentate gyrus in response to various pathologic insults (O'Brien et al., 1999; Reti et al., 2002). This differential expression suggests that NP1 and Narp serve distinct functions in different neuronal populationssubpopulations. It is possible that selective induction of NP1 in certain subpopulations of neurons reflects their particular vulnerability to injury. On the basis of their structural and sequence similarities, we asked whether NP1 is similar to Narp in interact-
A

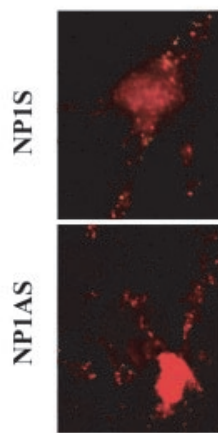

GluR1

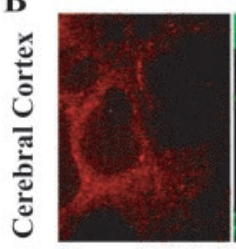

GluR1

(Texas red)
B
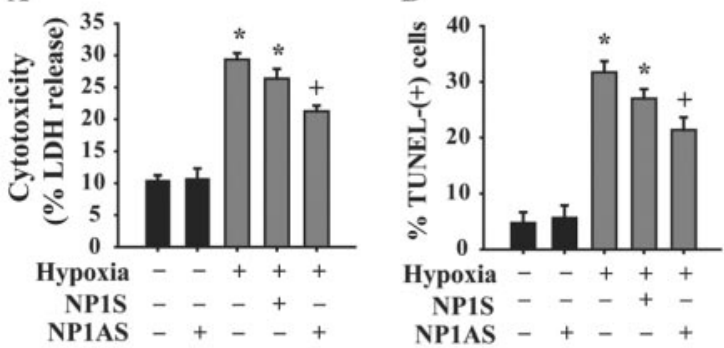

C

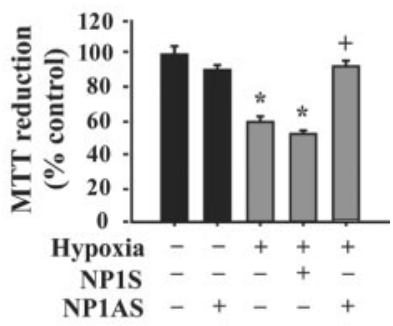

Figure 6. NP1 antisense (NP1AS) oligodeoxyribonucleotides prevent hypoxia-induced neuronal death in primary cortical cultures. Degree of cell death was assessed by LDH release $(A)$, TUNEL-staining $(B)$, and mitochondrial MTT reduction $(C)$ in cortical neurons transfected with NP1AS (antisense) or NP1S (sense) oligonucleotides. NP1AS significantly inhibited hypoxiainduced neuronal death in cortical cultures but not the NP1S. Data represent mean \pm SEM $\left(n=8 ;{ }^{*} p<0.001\right.$ vs normoxia control; ${ }^{+} p<0.001$ vs hypoxia group).

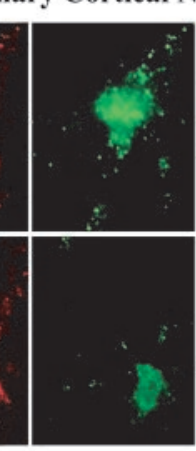

NP1

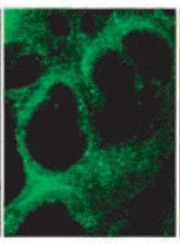

NP1

(FITC)

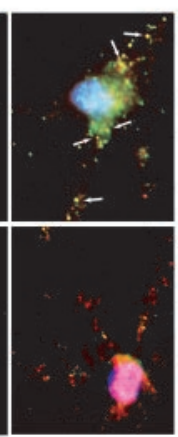

Overlap

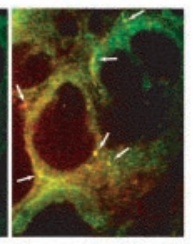

Overlap
C

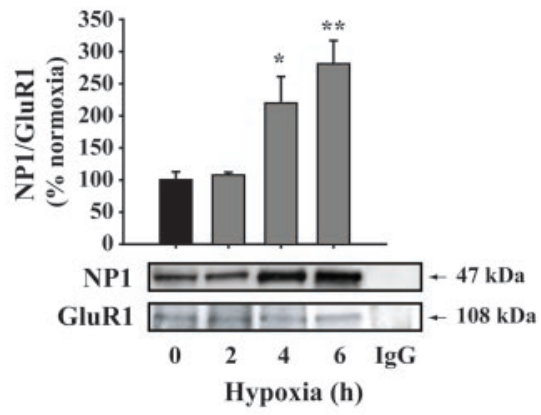

Figure 7. Colocalization and coimmunoprecipitation of NP1 protein with GluR1 AMPA receptor subunits. Primary cortical cultures were established at low density $\left(30-40 \times 10^{3} \mathrm{cells} / \mathrm{cm}^{2}\right)$ on coverslips as described in Materials and Methods. A, Live immunostaining of $7 \mathrm{~d}$ cultured cortical neurons with antibodies to NP1 (1:200) and GluR1 (1:150). Neurons were permeabilized and stained with secondary antibodies (FITC-conjugated goat anti-mouse for NP1; green fluorescence) and Texas Red-conjugated goat anti-rabbit for GluR1; red fluorescence). Digitized individual and overlapped fluorescence images show colocalization of NP1 and GluR1 subunits (top panels). Cultures transfected with NP1AS showed a chromatic decrease in NP1-specific immunofluorescence and a near total absence of NP1-GluR1 colocalization (bottom panels) relative to sense-treated neurons. B, Double immunofluorescence staining of NP1 and GluR1 in rat brain sections from control and $\mathrm{HI}$ animals visualized under confocal microscopy. Merged images $(100 \times)$ show NP1 and GluR1 colocalization. C, SDS-PAGE and immunoblotting of GluR1 immunoprecipitates from total cellular extracts revealed a time-dependent increase in NP1 co-precipitation in response to hypoxia $(0-6 \mathrm{hr})$ compared with normoxic neurons. IgG immunoprecipitates showed no evidence of NP1- and GluR1-specific bands. The ratio of NP1 over actin intensity was expressed as percentage of control normoxia. Data represent mean $\pm \operatorname{SEM}\left(n=4 ;{ }^{*} p<0.01 ;{ }^{* *} p<0.001\right.$ vs control normoxia). Representative immunoblots for NP1 and GluR1 are displayed.

ing with glutamate receptors (O'Brien et al., 1998, 1999, 2002). We found that NP1 colocalizes and physically associates with the fast excitatory GluR1 AMPA receptors and that hypoxia induces a time-dependent increase in the NP1-GluR1 interactions. Thus hypoxia recruits NP1 protein to GluR1 subunits concurrent with the hypoxic excitotoxic cascade. Furthermore, the disappearance of NP1-specific immunostaining without a concurrent loss of GluR1-specific clusters in NP1AS-transfected neurons suggests that, in contrast to Narp, NP1 may not play a substantial role in the formation or stabilization of GluR1 clusters. Rather we pro- 
A

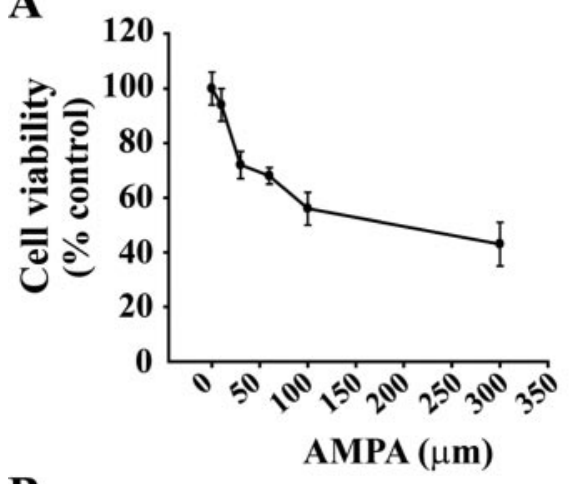

B

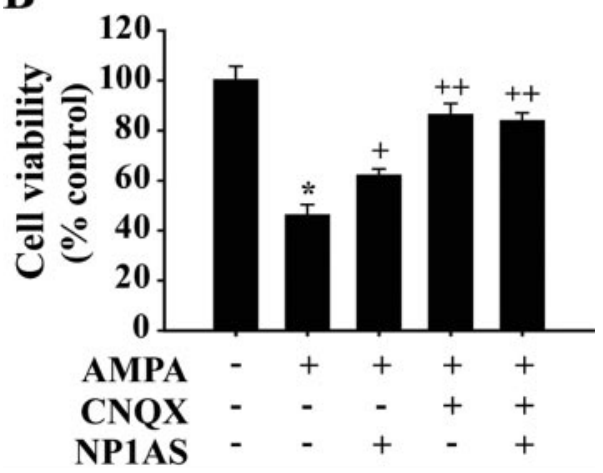

Figure 8. NP1 antisense ODNs inhibit AMPA-induced neuronal death. $A$, Primary cortical neurons cultured for $6-8 \mathrm{~d}$ in vitro were exposed to various concentrations of AMPA (10-300 $\mu \mathrm{M})$ for $24 \mathrm{hr}$. Measurement of neuronal viability by MTT assay revealed an AMPA concentration-dependent increase in neuronal death in primary cortical cultures. $B$, Protection of cortical neurons against AMPA-induced neuronal death by CNQX, a specific AMPA receptor antagonist, and by NP1AS. Neuronal cultures were transfected with either NP1AS or NP1S and $\sim 30 \mathrm{hr}$ later cells were exposed to $100 \mu \mathrm{M}$ AMPA or PBS as control in the presence or absence of CNQX. Pretreatment with CNQX completely attenuated AMPA-induced death, and cortical cultures transfected with NP1AS were partially protected against AMPA-induced death as determined by MTT assay. Data represent mean $\pm \operatorname{SEM}\left(n=8\right.$; ${ }^{*} p<0.001$ vs normoxia controls; ${ }^{++} p<0.001,{ }^{+} p=0.039$ vs AMPA).

pose that through interactions with GluR1 clusters, NP1 modulates the function of AMPA receptors in a manner whereby increased NP1-GluR1 interactions sensitize neurons to hypoxiainduced excitotoxic death. In support of this, we found that NP1AS protected against AMPA-induced neuronal death, demonstrating a direct link between NP1 function and AMPA receptor (GluR1)-mediated neuronal death. In comparison to that observed against hypoxia-induced neuronal death, however, NP1AS only partially protected against AMPA-induced death. This quantitative difference in protection by NP1AS might be explained by the difference between the complex cascade of events initiated by hypoxia compared with the relatively simple AMPA-induced injury. In addition, NP1 may interact with other subunits of excitatory AMPA and NMDA subtypes of glutamate receptors that are activated during hypoxia in addition to GluR1, which is a subject of ongoing investigations.

In summary, our findings point to a mechanism by which NP1 modulates hypoxic-ischemic injury at the level of the excitatory cascade involving GluR1 and potentially other glutamate receptor subtypes. This is the first evidence for a pathophysiologic role of NP1 in central neurons and suggests a new molecular target for preventing hypoxic-ischemic neuronal death. These very novel results could lead to more effective neuroprotective strategies against hypoxic-ischemic brain injury. Furthermore, our results could lead to important new insights into a role for NP1 and NP1-GluR1 interactions in normal excitatory synaptic function during synaptogenesis, synaptic plasticity, and learning in the developing brain.

\section{References}

Aoki C, Venkatesan C, Go CG, Mong JA, Dawson TM (1994) Cellular and subcellular localization of NMDA-R1 subunit immunoreactivity in the visual cortex of adult and neonatal rats. J Neurosci 14:5202-5222.

Barks JD, Silverstein FS (1992) Excitatory amino acids contribute to the pathogenesis of perinatal hypoxic-ischemic brain injury. Brain Pathol 2:235-243.

Baude A, Nusser Z, Molnar E, Mcllhinney RA, Somogyi P (1995) Highresolution immunogold localization of AMPA type glutamate receptor subunits at synaptic and non-synaptic sites in rat hippocampus. Neuroscience 69:1031-1055.

Bittigau P, Sifringer M, Pohl D, Stadthaus D, Ishimaru M, Shimizu H, Ikeda M, Lang D, Speer A, Olney JW, Ikonomidou C (1999) Apoptotic neurodegeneration following trauma is markedly enhanced in the immature brain. Ann Neurol 45:724-735.

Bottazzi B, Vouret-Craviari V, Bastone A, De Gioia L, Matteucci C, Peri G, Spreafico F, Pausa M, D’Ettorre C, Gianazza E, Tagliabue A, Salmona M, Tedesco F, Introna M, Mantovani A (1997) Multimer formation and ligand recognition by the long pentraxin PTX3. Similarities and differences with the short pentraxins C-reactive protein and serum amyloid P component. J Biol Chem 272:32817-32823.

Chen J, Nagayama T, Jin K, Stetler RA, Zhu RL, Graham SH, Simon RP (1998) Induction of caspase-3-like protease may mediate delayed neuronal death in the hippocampus after transient cerebral ischemia. J Neurosci 18:4914-4928.

Choi DW, Rothman SW (1990) The role of glutamate neurotoxicity in hypoxic-ischemic neuronal death. Annu Rev Neurosci 13:171-182.

Cox JA, Felder CC, Hennebury RC (1990) Differential expression of excitatory amino acid receptor subtypes in cultured cerebellar neurons. Neuron 4:941-947.

Craig AM, Blackstone CD, Huganir RL, Banker G (1993) The distribution of glutamate receptors in cultured rat hippocampal neurons: postsynaptic clustering of AMPA-selective subunits. Neuron 10:1055-1068.

DeGregorio-Rocasolano N, Gasull T, Trullas R (2001) Overexpression of neuronal pentraxin 1 is involved in neuronal death evoked by low $\mathrm{K}(+)$ in cerebellar granule cells. J Biol Chem 276:796-803.

D’Mello SR, Galli C, Ciotti T, Calissano P (1993) Induction of apoptosis in cerebellar granule neurons by low potassium: inhibition of death by insulin-like growth factor I and cAMP. Proc Natl Acad Sci USA 90:10989-10993.

Dodds DC, Omeis IA, Cushman SJ, Helms JA, Perin MS (1997) Neuronal pentraxin receptor, a novel putative integral membrane pentraxin that interacts with neuronal pentraxin 1 and 2 and taipoxin-associated calcium-binding protein 49. J Biol Chem 272:21488-21494.

Dudek H, Datta SR, Franke TF, Birnbaum MJ, Yao R, Cooper GM, Segal RA, Kaplan DR, Greenberg ME (1997) Regulation of neuronal survival by the serine-threonine protein kinase Akt. Science 275:661-665.

Gewurz H, Zhang XH, Lint TF (1995) Structure and function of the pentraxins. Curr Opin Immunol 7:54-64.

Goodman AR, Cardozo T, Abagyan R, Altmeyer A, Wisniewski HG, Vilcek J (1996) Long pentraxins: an emerging group of proteins with diverse functions. Cytokine Growth Factor Rev 7:191-202.

Hossain MA, Fielding KE, Trescher WH, Ho T, Wilson MA, Laterra J (1998) Human FGF-1 gene delivery protects against quinolinate-induced striatal and hippocampal injury in neonatal rats. Eur J Neurosci 10:2490-2499.

Hossain MA, Bailone JC, Gomez R, Laterra J (2002) Neuroprotection by scatter factor/hepatocyte growth factor and FGF-1 in cerebellar granule neurons is phosphatidylinositol 3-kinase/Akt-dependent and MAPK/ CREB-independent. J Neurochem 81:365-378.

Jin K, Mao XO, Zhu Y, Greenberg DA (2002) MEK and ERK protect hypoxic cortical neurons via phosphorylation of Bad. J Neurochem 80:119-125.

Johnston MV (1997) Hypoxic and ischemic disorders of infants and children. Lecture for 38th meeting of Japanese Society of Child Neurology, Tokyo, Japan, July 1996. Brain Dev 19:235-239.

Johnston MV (2001) Excitotoxicity in neonatal hypoxia. Ment Retard Dev Disabil Res Rev 7:229-234. 
Johnston MV, Trescher WH, Ishida A, Nakajima W (2001) Neurobiology of hypoxic-ischemic injury in the developing brain. Pediatr Res 49:735-741.

Kirkpatrick LL, Matzuk MM, Dodds DC, Perin MS (2000) Biochemical interactions of the neuronal pentraxins. Neuronal pentraxin (NP) receptor binds to taipoxin and taipoxin-associated calcium-binding protein 49 via NP1 and NP2. J Biol Chem 275:17786-17792.

Laemmli UK (1970) Cleavage of structural proteins during the assembly of the head of bacteriophage T4. Nature 227:680-685.

Lau LF, Huganir RL (1995) Differential tyrosine phosphorylation of $\mathrm{N}$-methyl-D-aspartate receptor subunits. J Biol Chem 270:20036-20041.

Li M, Wang X, Meintzer MK, Laessig T, Birnbaum MJ, Heidenreich KA (2000) Cyclic AMP promotes neuronal survival by phosphorylation of glycogen synthase kinase 3beta. Mol Cell Biol 20:9356-9363.

Lorenz JM, Wooliever DE, Jetton JR, Paneth N (1998) A quantitative review of mortality and developmental disability in extremely premature newborns. Arch Pediatr Adolesc Med 152:425-435.

Martin LJ, Al-Abdulla NA, Brambrink AM, Kirsch JR, Sieber FE, PorteraCailliau C (1998) Neurodegeneration in excitotoxicity, global cerebral ischemia, and target deprivation: a perspective on the contributions of apoptosis and necrosis. Brain Res Bull 46:281-309.

McDonald JW, Johnston MV (1990) Physiological and pathophysiological roles of excitatory amino acids during central nervous system development. Brain Res Brain Res Rev 15:41-70.

McDonald JW, Silverstein FS, Johnston MV (1988) Neurotoxicity of $\mathrm{N}$-methyl-D-aspartate is markedly enhanced in developing rat central nervous system. Brain Res 459:200-203.

Nakajima W, Ishida A, Lange MS, Gabrielson KL, Wilson MA, Martin LJ, Blue ME, Johnston MV (2000) Apoptosis has a prolonged role in the neurodegeneration after hypoxic ischemia in the newborn rat. J Neurosci 20:7994-8004

Namura S, Zhu J, Fink K, Endres M, Srinivasan A, Tomaselli KJ, Yuan J, Moskowitz MA (1998) Activation and cleavage of caspase-3 in apoptosis induced by experimental cerebral ischemia. J Neurosci 18:3659-3668.

Northington FJ, Ferriero DM, Flock DL, Martin LJ (2001a) Delayed neurodegeneration in neonatal rat thalamus after hypoxia-ischemia is apoptosis. J Neurosci 21:1931-1938.

Northington FJ, Ferriero DM, Graham EM, Traystman RJ, Martin LJ (2001b) Early neurodegeneration after hypoxia-ischemia in neonatal rat is necrosis while delayed neuronal death is apoptosis. Neurobiol Dis 8:207-219.

O’Brien R, Xu D, Mi R, Tang X, Hopf C, Worley P (2002) Synaptically targeted Narp plays an essential role in the aggregation of AMPA receptors at excitatory synapses in cultured spinal neurons. J Neurosci 22:4487-4498.

O’Brien RJ, Mammen AL, Blackshaw S, Ehlers MD, Rothstein JD, Huganir RL (1997) The development of excitatory synapses in cultured spinal neurons. J Neurosci 17:7339-7350.
O’Brien RJ, Lau LF, Huganir RL (1998) Molecular mechanisms of glutamate receptor clustering at excitatory synapses. Curr Opin Neurobiol 8:364-369.

O’Brien RJ, Xu D, Petralia RS, Steward O, Huganir RL, Worley P (1999) Synaptic clustering of AMPA receptors by the extracellular immediateearly gene product Narp. Neuron 23:309-323.

Omeis IA, Hsu YC, Perin MS (1996) Mouse and human neuronal pentraxin 1 (NPTX1): conservation, genomic structure, and chromosomal localization. Genomics 36:543-545.

Petralia RS, Wenthold RJ (1992) Light and electron immunocytochemical localization of AMPA-selective glutamate receptors in the rat brain. J Comp Neurol 318:329-354.

Portera-Cailliau C, Price DL, Martin LJ (1997a) Excitotoxic neuronal death in the immature brain is an apoptosis-necrosis morphological continuum. J Comp Neurol 378:70-87.

Portera-Cailliau C, Price DL, Martin LJ (1997b) Non-NMDA and NMDA receptor mediated excitotoxic neuronal deaths in adult brain are morphologically distinct: further evidence for an apoptosis-necrosis continuum. J Comp Neurol 378:88-104.

Puka-Sundvall M, Sandberg M, Hagberg H (1997) Brain injury after hypoxia-ischemia in newborn rats: relationship to extracellular levels of excitatory amino acids and cysteine. Brain Res 750:325-328.

Reti IM, Reddy R, Worley PF, Baraban JM (2002) Prominent Narp expression in projection pathways and terminal fields. J Neurochem 82:935-944.

Rice III JE, Vannucci RC, Brierley JB (1981) The influence of immaturity on hypoxic-ischemic brain damage in the rat. Ann Neurol 9:131-141.

Schlimgen AK, Helms JA, Vogel H, Perin MS (1995) Neuronal pentraxin, a secreted protein with homology to acute phase proteins of the immune system. Neuron 14:519-526.

Trescher WH, Ishiwa S, Johnston MV (1997) Brief post-hypoxic-ischemic hypothermia markedly delays neonatal brain injury. Brain Dev 19:326-338.

Tsui CC, Copeland NG, Gilbert DJ, Jenkins NA, Barnes C, Worley PF (1996) Narp, a novel member of the pentraxin family, promotes neurite outgrowth and is dynamically regulated by neuronal activity. J Neurosci 16:2463-2478.

Walter KA, Hossain MA, Luddy C, Goel N, Reznick TE, Laterra J (2002) Scatter factor/hepatocyte growth factor stimulation of glioblastoma cell cycle progression through G1 c-Myc dependent, and independent of p27 suppression cdk2 activation, or E2F1-dependent transcription. Mol Cell Biol 22:2703-2715.

Wang Y, Chang CF, Morales M, Chou J, Chen HL, Chiang YH, Lin SZ, Cadet JL, Deng X, Wang JY, Chen SY, Kaplan PL, Hoffer BJ (2001) Bone morphogenetic protein-6 reduces ischemia-induced brain damage in rats. Stroke 32:2170-2178. 